\title{
DESIGN, FORMULATION AND EVALUATION OF CELECOXIB SOLID DISPERSIONS PREPARED BY THE SOLVENT- EVAPORATION TECHNIQUE
}

\author{
Yasmin I. Mortagi ${ }^{1}$, Shedid G. Shedid ${ }^{2}$, Mamdouh M. Ghourab ${ }^{2}$ and Ahmed M.S. \\ Ahmed $^{3}$ \\ ${ }^{1}$ Department of Pharmaceutics, Faculty of Pharmacy and Pharmaceutical Industries, Sinai \\ University, El-Arish, North Sinai, Egypt. \\ ${ }^{2}$ Department of Pharmaceutics, Faculty of Pharmacy, Suez Canal University, Ismailia, \\ Egypt. \\ ${ }^{3}$ Department of Pharmaceutics and Industrial Pharmacy, Faculty of Pharmacy, Al-Azhar \\ University, Nasr City, Cairo, Egypt.
}

\begin{abstract}
The aim of the present study was to improve dissolution of poorly water-soluble Celecoxib by solid dispersion technique using water soluble carriers. Solid dispersions of Celecoxib were prepared with different polymers or carriers such as Hydroxy Propyl Beta Cyclodextrin, polyvinylpyrrolidone (PVP K30) and Urea. Solid dispersions were formulated in drug polymer ratio 1:2.5, 1:5, 1:7.5 and 1:10 using solvent evaporation method. The prepared formulae were assayed for drug content, production yield and micromeritics properties. Dissolution profiles were done in water containing $1 \%$ sodium lauryl sulphate and the in-vitro release was ranked according to the \% drug released after 60 and 120 minutes. The results indicated that all of the formulated solid dispersions displayed better dissolution profiles as compared to the pure drug. Formula containing drug to HP- $\beta$-CD $(1: 10)$ was ranked first and gave the best results out of the 12 solid dispersion formulae prepared.
\end{abstract}

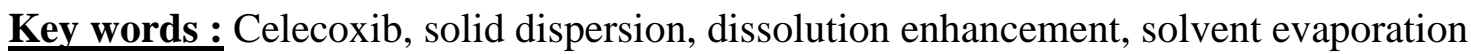

\section{INTRODUCTION}

The term 'solid dispersion' has been utilized to describe a family of dosage forms whereby the drug is dispersed in a biologically inert matrix, usually with a view to enhancing oral bioavailability. Another definition was 'molecular mixtures of poorly water soluble drugs in hydrophilic carriers.

First description of solid dispersions was from Sekiguchi and Obi (1961). They noted that the formulation of eutectic mixtures improve the rate of drug release and, consequently, the bioavailability of poorly water soluble drugs (Sekiguchi et al., 1964). In the late sixties a second generation of solid dispersions appeared, containing amorphous carriers instead of crystalline ones. Recently, it has been shown that the dissolution profile can be improved if the carrier has surface activity or self-emulsifying properties, therefore third generation solid dispersions appeared. These contain a surfactant carrier, or a mixture of amorphous polymers and surfactants as carriers.

The most commonly used hydrophilic carriers for solid dispersions include polyvinylpyrrolidone (Paradkar et al., 2004; Ambike et al., 2004), polyethylene glycols (Samy et al., 2010), Urea (Punitha et al., 2009) and cyclodextrins (CDs) that comprises of a series of cyclic oligosaccharides compounds, and several members of this family are used industrially in pharmaceutical, chemical, and food science applications (Maestre et al., 2007). 
Solid dispersion can be prepared by four methods. The first one is the solvent evaporation method. Various drugs are formulated as solid dispersions by solvent method, the most recent candidates are: Aceclofenac (Dahiya, 2010), Tacrolimus (Joe et al., 2010), Allopurniol (Samy et al., 2010), and Isradipine (Tran et al., 2010). Another common process is the co-precipitation method, in which a non-solvent is added drop wise to the drug and carrier solution, under constant stirring. In the course of the non-solvent addition, the drug and carrier are co-precipitated to form microparticles (Pouton, 2006).

The second method is the Fusion method which is sometimes referred to as the melt method, which is correct only when the starting materials are crystalline. The matrix consisted of sulfathiazole and urea as solid dispersion which was melted using a physical mixture at the eutectic composition, followed by a cooling step. Some of recent solid dispersions formed by fusion method are: glibenclamide (Patel et $\boldsymbol{a l}$., 2010A), gliclazide (Venkatesh et al., 2010), carbamazipine and nifidipine (Bley $\boldsymbol{e t}$ al., 2010), and Furosemide (Patel et al., 2010B)

Hot melt extrusion is the third method of preparation. Melt extrusion is essentially the same as the fusion method except that intense mixing of the components is induced by the extruder. Yang et al. (2010) prepared acetaminophen as solid dispersion by hot melt extrusion.

Supercritical fluid methods is a recent method which mostly applied with carbon dioxide (CO2), which is used as either a solvent for drug and matrix or as an anti-solvent. When supercritical $\mathrm{CO} 2$ is used as solvent, matrix and drug are dissolved and sprayed through a nozzle, into an expansion vessel with lower pressure and particles are immediately formed.

In spite of almost several years of research on solid dispersions, their commercial application is limited. Only a few products have been marketed so far. Amongst these are: Gris-PEG (Novartis), griseofulvin in PEG; Cesamet (Lily), nabilone in PVP; Sporanox (Janssen Pharmaceutica/J\&J), itraconazole in HPMC and PEG 20,000 sprayed on sugar spheres.

NSAIDs are the most widely prescribed medications in the world. All (NSAIDs) including selective COX-2 inhibitors, are antipyretic, analgesics, and anti-inflammatory. The mechanism of action of NSAIDs has been attributed to their ability to inhibit the cyclooxygenase enzyme (COX). Out of the 2 isoforms of cyclooxygenase, COX -1 is responsible for mediating the production of prostaglandin while COX-2 is primarily associated with inflammation, pain, and fever. The traditional NSAIDs are non selective COX inhibitors. COX-2 selective NSAIDs are, therefore, ideal anti-inflammatory drugs with minimum drug related side effects, since they spare COX-1 activity.

Celecoxib was our drug of choice which is the first specific inhibitor of cycloxygenase-2 (COX-2) to be approved by the United States Food and Drug Administration (FDA), in 1998. The aqueous solubility of CXB is low (3 to 7 $\mu \mathrm{g} / \mathrm{mL}$ ) when determined in vitro at $\mathrm{pH} 7$ and $40^{\circ} \mathrm{C}$ as its chemical structure shows high non-polar characteristics. The oral bioavailability of CXB is between $22 \%$ and $40 \%$. Thus, it is important to enhance the solubility and dissolution rate of CXB to improve its overall oral bioavailability. There are various techniques for enhancement of CXB solubility as using its amorphous form (Chawlaa, 2003), cosolvency (Seedher and Bhatia, 2003), solid dispersion (Dixit and Nagarsenker, 2007), nanoemulsion (Shakeel et al., (2008), nanoparticles (Patlolla et al., 2010) and inclusion complex (Chowdary and Srinivas, 2006). 
The aim of this paper was to prepare Celecoxib solid dispersions using HP- $\beta-C D$, PVP K30 and Urea in order to enhance its solubility, in-vitro release and hence its bioavailability.

\section{MATERIALS}

Celecoxib and HP- $\beta$-CD kindly donated by Medical Union Pharmaceuticals, Abu Sultan, Ismailia, (Egypt). PVP k30, Winlab Leicestershire, (United Kingdom). Urea, Alpha Chemica, Mumbai, (India).Methanol, PureLab, Madison, (USA). Sodium Lauryl Sulfate (SLS), Alnasr Pharmaceutical Chemical Co., (Egypt).

\section{EQUIPMENT}

Hitachi, U-2900 U.V spectrophotometer (Japan). USP dissolution tester, six cup model, Apparatus II, Erwika. Apparatebau GmbH, (Germany). Sieve No. 60, and sieve No. 120, USA standard test sieve, ASTME-11. specification, Gilson company, 1NC 1-800-4441508 (USA). Electric balance, SARTORIUS, TE2145, 4 decimal, (Germany). Oven, Binder GmbH Bergster. 14 D-78532 Tuttlingen (Germany). Shaking water bath, Oldmixon Crescent, Weston-super-Mare, BS24 9BL, United Kingdom.

\section{METHODOLOGY}

\section{Preparation of Celecoxib solid dispersions by the Solvent evaporation method}

The calculated amount of Celecoxib and the employed polymers (HP- $\beta-C D$, PVP K30 and Urea) in different drug-polymer ratios (1:2.5, 1:5, 1:7.5 and 1:10) were weighed and mixed together in a porcelain dish. Twelf different formulae were prepared by the solvent evaporation method. The mixture was dissolved in the least amount of methanol as a common solvent. Then the solvent was evaporated in oven at temperature $45^{\circ} \mathrm{C}$ till complete evaporation. The solid dispersions prepared were pulverized in a mortar and sieved. The fraction of the powder that passed through $200 \mu \mathrm{m}$ and retained on a $125 \mu \mathrm{m}$ sieve was collected, stored in a desiccator and used for further investigations.

\section{Production yield and drug content of Celecoxib solid dispersions}

\section{The production yield}

The production yields of the prepared Celecoxib solid dispersions were studied, since it measures the actual weight of the prepared solid dispersion (drug + polymer). This value was calculated by dividing the actual yield of the solid dispersion produced (before sieving) over the theoretical yield and multiplied by 100 .

Production yield $=\frac{\text { Actual yield of solid dispersion }}{\text { Theoretical yield of solid dispersion }} \times 100$

\section{The drug content}

A specific amount of the prepared Celecoxib solid dispersion equivalent to $5 \mathrm{mg}$ drug was dissolved in $50 \mathrm{ml}$ methanol to produce stock solution $(100 \mu \mathrm{g} / \mathrm{ml})$. One $\mathrm{ml}$ of the stock solution was withdrawn and completed to $10 \mathrm{ml}$ using methanol. The concentration of this solution was $(10 \mu \mathrm{g} / \mathrm{ml})$. The solution was assayed spectrophotometrically at $252 \mathrm{~nm}$ for calculating the Celecoxib content. The polymers did not show interference with the absorbance of the drug at this wavelength.

\section{Micromeritic properties of the prepared solid dispersions}

The prepared solid dispersions were evaluated through determination of the following parameters: 


\section{Densities of solid dispersions}

Both bulk density $\left(D_{b}\right)$ and tapped density $\left(D_{t}\right)$ were determined. A quantity of $1 \mathrm{~g}$ solid dispersion powder was introduced into a $10 \mathrm{ml}$ measuring cylinder. The initial volume was observed, and then the cylinder was allowed to stroke. The tapping was continued until no further change in volume was noted. $D_{b}$ and $D_{t}$ were calculated using the following formulae:

$\mathrm{D}_{\mathrm{b}}=\mathrm{Wt} /$ bulk volume $=\mathrm{Wt} / \mathrm{V}_{\mathrm{b}}$

$\mathrm{D}_{\mathrm{t}}=\mathrm{Wt} /$ tapped volume $=\mathrm{Wt} / \mathrm{V}_{\mathrm{t}}$

\section{Hausner's Ratio}

It is the ratio between bulk density and tapped density. It gives an idea about the flow characters of powder particles.

Hausner ratio $=\mathrm{D}_{\mathrm{t}} / \mathrm{D}_{\mathrm{b}}$

\section{Compressibility percent (Carr's Index)}

Compressibility is indirectly related to the relative flow rate, cohesiveness, and particle size of a powder. The compressibility percent of a material can be estimated as:

Compressibility $\%=\left(D_{t}-D_{b} / D_{t}\right) \times 100$

\section{Angle of Repose}

It was measured by passing the solid dispersion powder through a funnel which was maintained at a fixed height in all experiments. The height $(\mathrm{h})$ and radius ( $\mathrm{r}$ ) of the cone were determined. The angle of repose was calculated from the following equation:

$\operatorname{Tan} \Theta=h / r$

\section{In-vitro release study of Celecoxib solid dispersions}

\section{From Hard gelatin capsules}

The dissolution behaviors of the prepared 12 formulae of Celecoxib solid dispersions were compared with the Celecoxib powder. The dissolution studies were performed by USP dissolution tester, apparatus I (basket method).

An accurately weighed amount of prepared solid dispersion equivalent to $100 \mathrm{mg}$ of Celecoxib was placed in Hard gelatin capsule. Each capsule was placed in a basket in $900 \mathrm{ml}$ of water containing $1 \%$ sodium lauryl sulphate. The basket was rotated at $100 \mathrm{rpm}$. The temperature of the in-vitro release medium was maintained at $37^{\circ} \mathrm{C} \pm 0.5^{\circ} \mathrm{C}$. Each sample was run in triplicate in which 5 milliliters aliquots were withdrawn at $10,20,30,45,60,90$ and 120 minutes and replaced by $5 \mathrm{ml}$ of fresh pre-warmed water containing 1\% SLS. Samples were analyzed spectrophotometrically at the predetermined $\lambda_{\max }$ using water containing $1 \%$ SLS as a blank. The cumulative percentage drug released was calculated.

The experiments were conducted in triplicates and the mean \pm SD was calculated using Microsoft office excel, 2007

The data of the in-vitro release of pure Celecoxib and Celecoxib solid dispersion was treated by different kinetic orders or systems to explain the release mechanism for each formula. So, the studied formulations of Celecoxib were subjected to zero, first and Higuchi's diffusion model (Higuchi, 1963). The kinetic parameters and correlation coefficient were calculated for the in-vitro release of Celecoxib. 


\section{RESULTS AND DISCUSSION}

\section{Preparation of Celecoxib by solid dispersion technique using solvent-evaporation method}

Celecoxib was formulated as solid dispersions using the solvent-evaporation technique. Three polymers were employed, i.e., HP- $\beta$-CD, PVP K30 and Urea in different drug-polymer ratios (1:2.5, 1:5, 1:7.5 and 1:10). Twelf different formulae of Celecoxib solid dispersions were prepared by the above method. Table (1) contains the suggested formulae of Celecoxib.

The formed solid dispersions varied in their physical properties according to the type of polymer used and the proportions of drug to polymer. Formulae containing PVP were more viscous, sticky and more difficult to be sieved than formulae containing HP- $\beta-C D$ and Urea.

The lower the ratio of the drug to the polymer, the more elastic the solid dispersion was. This was consistent with the results of Tantishaiyakul $\boldsymbol{e t}$ al. (1999) which stated that piroxicam: PVP k90 ratios lower than 1:4 were not investigated due to the stickiness of the preparations with the increasing amount of the polymer.

Muralidhar et al., (2010) prepared solid dispersion of CXB and PVP K30 in a similar procedure to our thesis, CXB:PVPK-30 in 1:1, 1:2, 1:4, 1:6 weight ratios by means of solvent method; the same work was reported by Punitha et al., (2010) who prepared CXB-Mannitol solid dispersion by solvent evaporation technique; (Punitha et al., 2009) who prepared CXB-Urea by the solvent method; Ahuja et al. (2007) who prepared Refocoxib solid dispersions with PVP K25; Shavi and coworkers (2010) prepared the solid dispersions by dissolving the mixture of Gliclazide and the PVP K 30 at the weight ratios of 1:0.5, 1:0.75 and 1:1 w/w and Samy et al. (2010) used the solvent evaporation method to prepare solid dispersions of Allopurinol with different polymers (PVP K30 and PVP K90)

Table (1): Suggested formulae of Celecoxib [solid dispersions]

\begin{tabular}{|c|c|c|c|c|}
\hline Formula & CXB (mg) & $\begin{array}{c}\text { PVPk30 } \\
(\mathbf{m g})\end{array}$ & Urea (mg) & $\begin{array}{c}\text { HP- } \boldsymbol{\beta - C D} \\
(\mathbf{m g})\end{array}$ \\
\hline CXB-PVP(1:2.5) & 100 & 250 & & \\
\hline CXB-PVP(1:5) & 100 & 500 & & \\
\hline CXB-PVP(1:7.5) & 100 & 750 & & \\
\hline CXB-PVP(1:10) & 100 & 1000 & & \\
\hline CXB-U(1:2.5) & 100 & & 250 & \\
\hline CXB-U(1:5) & 100 & & 500 & \\
\hline CXB-U(1:7.5) & 100 & & 750 & \\
\hline CXB-U(1:10) & 100 & & 1000 & \\
\hline CXB-HP- $\boldsymbol{\beta}$-CD(1:2.5) & 100 & & & 250 \\
\hline CXB-HP- $\boldsymbol{\beta}-\mathbf{C D}(\mathbf{1 : 5})$ & 100 & & & 500 \\
\hline CXB-HP- $\boldsymbol{\beta}$-CD(1:7.5) & 100 & & & 750 \\
\hline CXB-HP- $\boldsymbol{\beta}$-CD(1:10) & 100 & & & 1000 \\
\hline
\end{tabular}

\section{The production yield}

The values of the production yield of the 12 formulae of Celecoxib solid dispersion before sieving were ranging from 90 to $99.62 \%$. Satisfactory reproducibility of results when repeating the preparations was observed. Table (2) shows the production yield of the prepared formulae. 
Formula CXB-Urea (1:7.5) gave the best value for the production yield while formula CXB-PVPK30 (1:2.5) gave the worst value. The obtained results were found to be in good agreement with the specifications of the official pharmacopeias (USP 30, 2007; BP, 2009).

The rank order for the production yield of CXB solid dispersions using different polymers and different drug-polymer ratios can be arranged, in descending order, as follows: CXB-Urea (1:7.5) > CXB-Urea (1:10) > CXB-Urea (1:5) > CXB-Urea (1:2.5) > CXB-

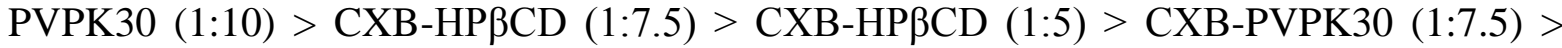
CXB-HP $\beta C D(1: 10)>$ CXB-HP $\beta C D(1: 2.5)>$ CXB-PVPK30 (1:5) > CXB-PVPK30 $(1: 2.5)$. The drug content

As shown in table (2), the drug content of different formulae ranged from $88.57 \%$ to $102.492 \%$. The obtained results were found to be in good agreement with the specifications of the official pharmacopeias (USP 30, 2007; BP, 2009).

The drug content of $\mathrm{CXB}$ in the solid dispersion formulae can be arranged in descending manner as follows: CXB-PVPK30 (1:2.5) > CXB-PVPK30 (1:10) > CXB-Urea $(1: 2.5)>$ CXB-HP- $\beta$-CD (1:2.5) > CXB-PVPK30 (1:7.5) > CXB-HP- $\beta$-CD $(1: 5)>$ CXBUrea (1:7.5) > CXB-PVPK30 (1:5) > CXB-Urea (1:5) > CXB-HP- $\beta$-CD $(1: 10)>$ CXB-HP$\beta$-CD (1:7.5) > CXB-Urea (1:10).

(Punitha et al., 2009) found that the drug content of (1:1) CXB-Urea solid dispersion was $99.25 \%$ and (1:5) was $98.61 \%$.

Table (2): Production yield and Drug Content for Celecoxib solid dispersions

\begin{tabular}{|l|c|c|c|c|}
\hline \multicolumn{1}{|c|}{ Formula Number } & $\begin{array}{c}\text { Production yield \% } \\
\text { (PY) }\end{array}$ & RO & $\begin{array}{c}\text { Drug Content (mg) } \\
\text { (DC) }\end{array}$ & RO \\
\hline CXB-PVP(1:2.5) & $90 \pm 0.02$ & 12 & $99.2 \pm 0.89$ & 1 \\
\hline CXB-PVP(1:5) & $91.83 \pm 0.15$ & 11 & $96.39 \pm 1.10$ & 8 \\
\hline CXB-PVP(1:7.5) & $94.36 \pm 0.08$ & 8 & $98.09 \pm 0.91$ & 5 \\
\hline CXB-PVP(1:10) & $97.84 \pm 0.13$ & 5 & $100.95 \pm 0.71$ & 2 \\
\hline CXB-U(1:2.5) & $98.57 \pm 0.17$ & 4 & $98.88 \pm 0.8$ & 3 \\
\hline CXB-U(1:5) & $99.38 \pm 0.14$ & 3 & $94.30 \pm 0.15$ & 9 \\
\hline CXB-U(1:7.5) & $99.62 \pm 0.24$ & 1 & $96.66 \pm 0.36$ & 7 \\
\hline CXB-U(1:10) & $99.55 \pm 0.16$ & 2 & $88.57 \pm 0.9$ & 12 \\
\hline $\begin{array}{l}\text { CXB-HP- } \boldsymbol{\beta}- \\
\text { CD(1:2.5) }\end{array}$ & $92.86 \pm 0.35$ & 10 & $101.52 \pm 0.57$ & 4 \\
\hline CXB-HP- $\boldsymbol{\beta}-\mathbf{C D}(\mathbf{1 : 5})$ & $95.125 \pm 0.12$ & 7 & $102.492 \pm 1.27$ & 6 \\
\hline $\begin{array}{l}\text { CXB-HP- } \boldsymbol{\beta}- \\
\text { CD(1:7.5) }\end{array}$ & $97.65 \pm 0.04$ & 6 & $90.634 \pm 1.10$ & 11 \\
\hline $\begin{array}{l}\text { CXB-HP- } \boldsymbol{\beta}- \\
\text { CD(1:10) }\end{array}$ & $93.66 \pm 0.21$ & 9 & $92.857 \pm 0.42$ & 10 \\
\hline
\end{tabular}

Micromeritic properties of Celecoxib solid dispersions

Direct method for calculating the flowability

Angle of repose $(\theta)$

The angle of repose has been used in several branches of sciences to characterize the flow properties of solids. Angle of repose is a characteristic related to interparticulate friction or resistance to movement between particles. Angle of repose results were reported to be very dependent upon the method used. Experimental difficulties may arise as a result of segregation of material and consolidation or aeration of a powder as the cone is formed. Despite its difficulties, the method continues to be used in the pharmaceutical industry, and a 
number of examples demonstrating its value in predicting manufacture problems appear in the literature.

The angle of repose is the constant, three dimensional angle (relative to the horizontal base) assumed by a cone-like pile of material formed by any of several different methods.

The angle of repose was found to affect the flowability of the particles or granules. The values less than $20^{\circ}$ exhibit excellent flowability; the values between 20 and $30^{\circ}$ show good flowability; the values between 30 and $34^{\circ}$ exhibit passable flowability; while the values above $34^{\circ}$ show very poor flowability (Bhowmik et al., 2009). USP specifications (USP 30, 2007) for the values of the angle of repose were different from the previous publication and these values are: $25-30$ excellent flow, $31-35^{\circ}$ indicates good flow, 36-40 the flowability of a powder is fair, $41-45^{\circ}$ passable flowability, $46-55^{\circ}$ poor, and $>55^{\circ}$ indicates very poor flow properties for a powder.

The values obtained for the angle of repose of the prepared Celecoxib solid dispersions ranged from $12.38^{\circ}$ to $19.5^{\circ}$, as shown in table (3). These values indicate that all formulae have good to excellent flowability. Good flowability was shown in all formulae. This may give indication that $\mathrm{CXB}$ solid dispersion is a good method for improving the flowability.

The ranking order of the angle of repose for the $\mathrm{CXB}$ solid dispersion formulae can be showed as follows : CXB-PVP (1:7.5), CXB-PVP (1:10), CXB-Urea (1:10), CXB-HP- $\beta$ CD (1:10), CXB-HP- $\beta$-CD (1:7.5), CXB-Urea (1:7.5), CXB-PVP (1:5), CXB-Urea (1:2.5), CXB-Urea (1:5), CXB-HP- $\beta$-CD (1:5), CXB-PVP (1:2.5), CXB-HP- $\beta$-CD (1:2.5).

\section{Indirect methods for calculating the flowability a- The bulk and tap densities}

The values obtained for the bulk densities of the prepared Celecoxib solid dispersions ranged from $0.501 \mathrm{CXB}-$ Urea $(1: 2.5)$ to $0.554 \mathrm{CXB}-\mathrm{HP}-\beta-\mathrm{CD}(1: 5)$. While the values obtained for the tap densities of the prepared $\mathrm{CXB}$ solid dispersions ranged from 0.546 CXB-PVP (1:10) to 0.685 CXB-Urea (1:5).

\section{b- The Hausner ratio}

The Hausner ratio is a number that is correlated to the flowability of a powder or granular material. The Hausner ratio is measured from the bulk and tapped density of the powder. The accepted scale of flowability of a powder was described in USP 30 (2007).

The value of the Hausner ratio was found to give indication about the flow properties of solid dispersion. The values less than 1.25 indicate better flowability than values more than 1.25 .

The values obtained for the Hauser ratio of the prepared Celecoxib solid dispersions ranged from1.039 CXB-PVP (1:7.5) to 2.219 CXB- HP- $\beta$-CD (1:2.5), as shown in table (3). So, the obtained results showed that four $\mathrm{CXB}$ solid dispersions have better flowability while the other eight CXB formulae showed passable flowability.

The Celecoxib solid dispersions can be arranged according to the Hausner ratio in descending manner as follows: CXB-HP- $\beta-C D(1: 2.5)>$ CXB- HP- $\beta$-CD $(1: 10)>$ CXBUrea $(1: 10)>$ CXB-Urea $(1: 2.5)>$ CXB-PVPK30 $(1: 10)>$ CXB-PVPK30 $(1: 2.5)>$ CXBUrea $(1: 5)>$ CXB-Urea $(1: 7.5)>$ CXB-HP- $\beta$-CD (1:7.5) $>$ CXB-HP- $\beta$-CD $(1: 5)>$ CXBPVPK30 (1:5) >CXB-PVPK30 (1:7.5).

\section{c- Compressibility \% (Carr's index)}

Compressibility percent is indirectly related to the relative flow rate, a compressible material will be less flowable. The value of the compressibility percent was found to affect the flow properties of solid dispersion. The values between 5 and 12 show excellent flowability; the values between 12 and 16 exhibit good flowability; the values between 18 and 21 show fair passable flowability; the values between 23 and 35 exhibit poor flowability; while the values between 33 and 38 exhibit very poor flowability (Bhowmik $\boldsymbol{e t}$ al., 2009). 
The obtained ranking order is the same as the obtained from the Hausner ratio data. The best Carr's index was 3.84 for CXB-PVPK30 (1:7.5), while the worst was 20 for CXBHP- $\beta$-CD (1:2.5), as shown in table (3).

The CXB solid dispersions can be arranged according to the compressibility percent in ascending manner as follows: CXB-PVPK30 (1:7.5) < CXB-PVPK30 (1:10) < CXBPVPK30 (1:5) < CXB-HP- $\beta$-CD $(1: 7.5)<$ CXB-HP- $\beta$-CD $(1: 10)<$ CXB-Urea $(1: 10)<$ CXB-Urea $(1: 7.5)<$ CXB-PVPK30 $(1: 2.5)<$ CXB-HP- $\beta$-CD $(1: 5)<$ CXB-Urea $(1: 2.5)<$ CXB-Urea (1:5) < CXB-HP- $\beta$-CD $(1: 2.5)$.

Tiwari et al., (2010) measured the bulk and tapped densities, angle of repose, hausners ratio and compressibility index of CXB-Sorbitol solid dispersions in various proportions and found it had a good flowability.

The rank order of CXB solid dispersions concerning the micromeritics properties (Angel of repose, Hausner Ratio and Carr's Index) was done. Formula CXB-PVPK30 (1:7.5) was found to be the best formulation of $\mathrm{CXB}$ solid dispersion followed by formula $\mathrm{CXB}$ PVPK30 (1:10).

Table (3): The data collected for the angle of repose, the bulk density, the tapped density, hausner ratio and compressibility \% of CXB solid dispersion formulae

\begin{tabular}{|c|c|c|c|c|c|}
\hline $\begin{array}{c}\text { Formula } \\
\text { Number }\end{array}$ & $\begin{array}{c}\text { Angle of } \\
\text { repose } \\
(\mathbf{A R})\end{array}$ & $\begin{array}{c}\text { Bulk density } \\
\left(\mathbf{g m} / \mathbf{c m}^{\mathbf{3}}\right)\end{array}$ & $\begin{array}{c}\text { Tapped } \\
\text { density } \\
\left(\mathbf{g m} / \mathbf{c m}^{\mathbf{3}}\right)\end{array}$ & $\begin{array}{c}\text { Hausner } \\
\text { ratio } \\
(\mathbf{H R})\end{array}$ & $\begin{array}{c}\text { Carr's } \\
\text { index } \\
(\mathbf{C I})\end{array}$ \\
\hline CXB-PVP(1:2.5) & $19.32 \pm 0.05$ & $0.530 \pm 0.002$ & $0.645 \pm 0.001$ & 1.216 & 17.78 \\
\hline CXB-PVP(1:5) & $16.41 \pm 0.06$ & $0.505 \pm 0.003$ & $0.594 \pm 0.003$ & 1.176 & 14.99 \\
\hline CXB-PVP(1:7.5) & $12.38 \pm 0.09$ & $0.531 \pm 0.003$ & $0.553 \pm 0.004$ & 1.039 & 3.84 \\
\hline CXB-PVP(1:10) & $12.82 \pm 0.04$ & $0.516 \pm 0.002$ & $0.546 \pm 0.004$ & 1.22 & 5.55 \\
\hline CXB-U(1:2.5) & $18.25 \pm 0.08$ & $0.501 \pm 0.002$ & $0.612 \pm 0.002$ & 1.23 & 18.033 \\
\hline CXB-U(1:5) & $18.6 \pm 0.03$ & $0.553 \pm 0.006$ & $0.685 \pm 0.004$ & 1.214 & 19.19 \\
\hline CXB-U(1:7.5) & $14.64 \pm 0.06$ & $0.534 \pm 0.003$ & $0.648 \pm 0.005$ & 1.21 & 17.65 \\
\hline CXB-U(1:10) & $13.09 \pm 0.02$ & $0.505 \pm 0.004$ & $0.611 \pm 0.002$ & 1.25 & 17.38 \\
\hline $\begin{array}{c}\text { CXB-HP- } \boldsymbol{\beta}- \\
\text { CD(1:2.5) }\end{array}$ & $19.5 \pm 0.05$ & $0.509 \pm 0.001$ & $0.636 \pm 0.002$ & 2.219 & 20 \\
\hline $\begin{array}{c}\text { CXB-HP- } \boldsymbol{\beta}- \\
\text { CD(1:5) }\end{array}$ & $19.21 \pm 0.10$ & $0.554 \pm 0.001$ & $0.674 \pm 0.003$ & 1.183 & 18.327 \\
\hline $\begin{array}{c}\text { CXB-HP- } \boldsymbol{\beta}- \\
\text { CD(1:7.5) }\end{array}$ & $14.52 \pm 0.08$ & $0.538 \pm 0.003$ & $0.637 \pm 0.003$ & 1.199 & 15.44 \\
\hline $\begin{array}{c}\text { CXB-HP- } \boldsymbol{\beta}- \\
\text { CD(1:10) }\end{array}$ & $13.67 \pm 0.04$ & $0.544 \pm 0.004$ & $0.653 \pm 0.003$ & 1.46 & 16.66 \\
\hline
\end{tabular}

\section{In-vitro release of Celecoxib solid dispersions from Hard gelatin capsule}

The in- vitro release refers to the rate of dissolving the drug from an intact dosage form. There are two reasons for performing these tests, one of them is to ensure product uniformity from batch to batch, the other reason is to predict the rate of drug absorption and/ or availability of the drug for absorption (Wagner, 1975).

In-vitro release studies were carried out at $37^{\circ} \mathrm{C}$ by the USP Dissolution Tester, Apparatus I (Rotating basket), and using $900 \mathrm{ml}$ of water containing 1\% SLS as the dissolution medium and at a rotation rate of $100 \mathrm{rpm}$. The in-vitro release of Celecoxib solid 
dispersion from the different suggested formulae was evaluated by measuring the percent of drug released from the Hard gelatin capsule.

The data obtained and calculated for this part are illustrated in figures (1-3). Pure Celecoxib yielded the slowest initial dissolution rate with only about $66.20 \%$ in 120 minutes.

Figure (1) shows the in-vitro release of pure Celecoxib and the prepared Celecoxib solid dispersion formulae from F1 to F4 using PVPK30. The influence of PVPK30 ratio was studied on the prepared formulae on the in-vitro release of Celecoxib using Hard gelatin capsule.

Formulae F1, F2 F3 and F4 contain different drug to PVPK30 ratios (1:2.5, 1:5, 1:7.5 and 1:10 respectively). The reported data for the in-vitro release of CXB after 120 minutes can be arranged in descending order as follows: CXB-PVPK30 $(1: 10)(96.93 \% \pm 1.47)>$ CXB-PVPK30 $(1: 7.5)(94.44 \% \pm 1.01)>$ CXB-PVPK30 $(1: 5)(93.5 \% \pm 0.95)>$ CXBPVPK30 (1:2.5) $(83.5 \% \pm 1.66)>$ CXB $(66.20 \% \pm 2.5)$. Muralidhar et al., (2010) reported that the dissolution of celecoxib has enhanced considerably from PVPK30 solid dispersions and the dissolution efficiency at 20 minutes was found to be 62.03 and 65.14 for CXBPVPK30(1:2) and CXB-PVPK30 (1:4), respectively.

Figure (2) shows the in-vitro release of pure $\mathrm{CXB}$ and the prepared CXB solid dispersion formulae from F5 to F8 using Urea. The influence of Urea was studied on the prepared formulae on the in-vitro release of CXB using hard gelatin capsule.

Formulae F5, F6, F7 and F8 contained different drug to Urea ratios (1:2.5, 1:5, 1:7.5 and 1:10 respectively). The reported data for the in-vitro release of CXB after 120 minutes can be arranged in descending order as follows: CXB-Urea $(1: 10)(79.96 \% \pm 0.45)>\mathrm{CXB}$ Urea - $(1: 7.5)(79.91 \% \pm 1.52)>$ CXB-Urea $(1: 5)(72.99 \% \pm 1.23)>$ CXB-Urea $(1: 2.5)$ $(70.40 \% \pm 1.37)>\mathrm{CXB}(66.20 \% \pm 2.5)$. Punitha et al., (2009) reported that in the solvent evaporation method it was observed that the increase in release rate of CXB-U (1:1, 1:3 and 1:5)was found to be $(37.86,53.35$ and 68.06) respectively. This may be due to impact of complexation and bond formation. This may lead improved solubility by reducing particle size.

Formulae F9, F10, F11 and F12 contained different drug to HP- $\beta$-CD ratios $(1: 2.5$, $1: 5,1: 7.5$ and 1:10 respectively). The reported data for the in-vitro release of CXB after 120 minutes can be arranged in descending order as follows: CXB- HP- $\beta$-CD (1:10) $(99 \% \pm$ $0.77)>$ CXB-HP- $\beta$-CD $(1: 7.5)(98.77 \% \pm 3.88)>$ CXB-HP- $\beta-C D(1: 5)(89.22 \% \pm 0.45)>$ CXB-HP- $\beta$-CD $(1: 2.5)(85.03 \% \pm 2.24)>\mathrm{CXB}(66.20 \% \pm 2.5)$ as showen in figure (3). Mallick et al., (2004) reported that the highest potency of the carriers was due to beta cyclodextrin in enhancing the dissolution rate of Nalidixic acid.

The rank order for the in-vitro release of CXB solid dispersions using different polymers and different drug-polymer ratios using the hard gelatin capsule is shown in table (4). CXB solid dispersion can be arranged, in descending order, as follows: CXB-HP- $\beta-C D$ $(1: 10)>$ CXB-HP- $\beta$-CD $(1: 7.5)>$ CXB-PVPK30 (1:10) > CXB-PVPK30 (1:7.5) > CXBHP- $\beta$-CD $(1: 5)>\quad$ CXB-PVPK30 (1:5) $>$ CXB-PVPK30 $(1: 2.5)=$ CXB-HP- $\beta-C D(1: 2.5)>$ CXB-Urea (1:10) > CXB-Urea (1:7.5) > CXB-Urea (1:5) > CXB-Urea (1:2.5).

Tantishaiyakul and coworkers (1999) studied the effect of PVP K90 and PVP K17 on the in vitro release of the piroxicam. They found that the Dissolution rates for solid dispersions were greater than those for piroxicam alone. The enhanced dissolution rates of solid dispersions may be due to many factors such as decreased particle size of drug (Ford $\boldsymbol{e t}$ al., 1986), specific form of drug (Simonelli, et al., 1976) in these solid dispersions in addition to the increase in drug wettability and preventing the aggregation of drug by the polymers.

A total conclusive rank order for production yield, drug content and the micromeritics properties and the in-vitro release of the Celecoxib solid dispersion is shown 
in table (5). From this rank order it was concluded that the best formula was CXB-PVPK30 in which the drug to polymer ratio was 1:10.

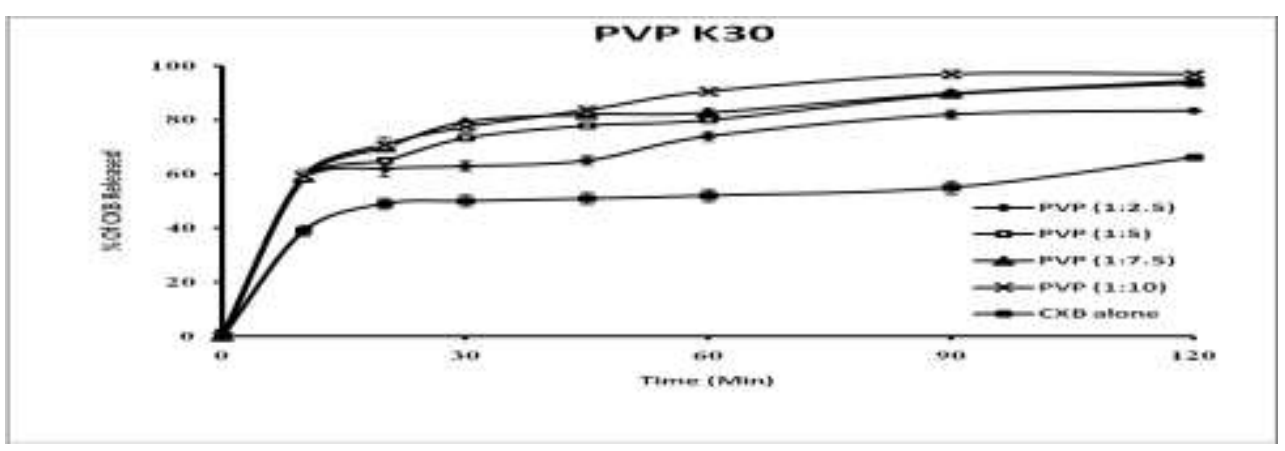

Figure (1): The effect of PVP K30 ratio on the in-vitro release of CXB soliddispersions using hard gelatin capsule (pure CXB + formulae 1-4)

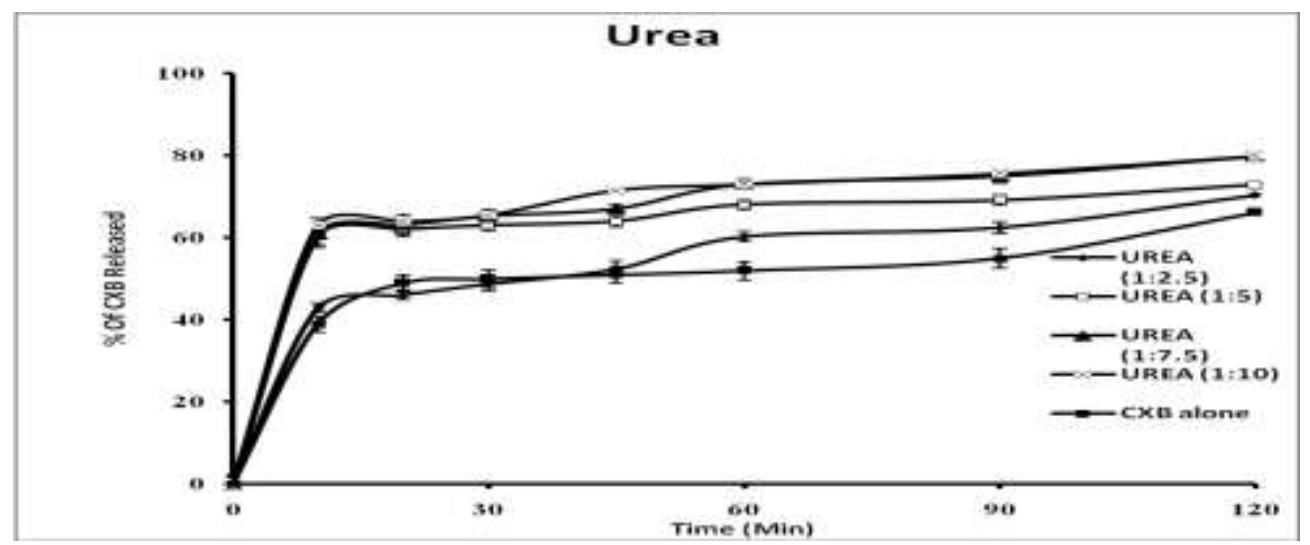

Figure (2): The effect of Urea ratio on the in-vitro release of CXB solid dispersions using hard gelatin capsule (pure CXB + formulae 5-8)

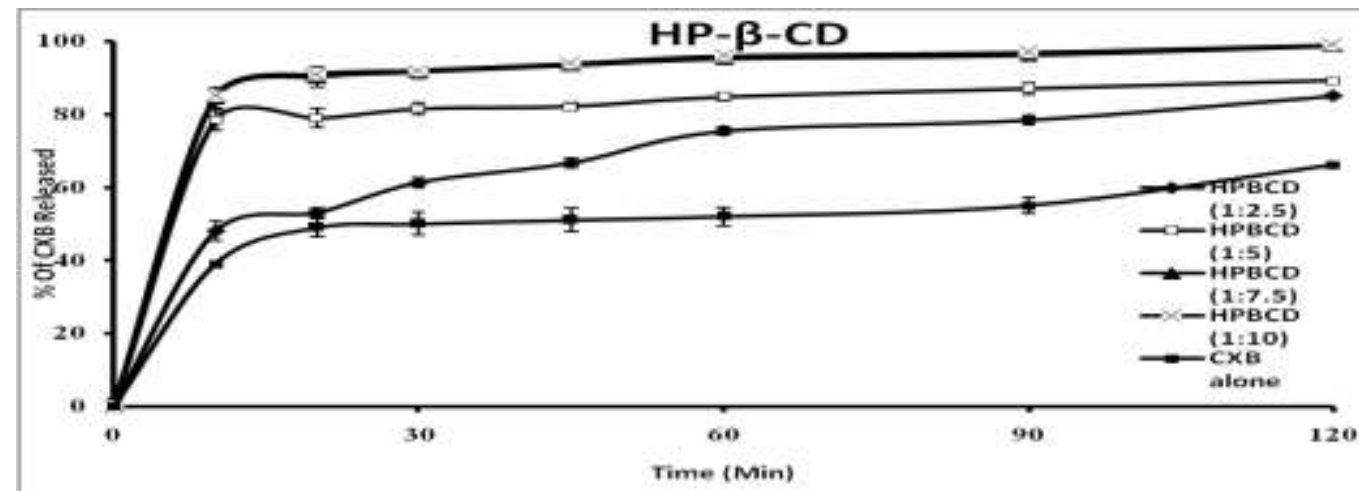

Figure (3): The effect of HP- $\beta$-CD ratio on the in-vitro release of CXB solid dispersions using hard gelatin capsule (pure CXB + formulae 9-12) 
Table (4): Rank Order for the in-vitro release of CXB solid dispersions using different polymers and different drug-polymer ratios using the hard gelatin capsule

\begin{tabular}{|c|c|c|c|c|c|c|}
\hline \multirow{2}{*}{ Formula No. } & \multicolumn{3}{|c|}{ \% release of CXB } & \multicolumn{2}{c|}{ Rank Order } \\
\cline { 2 - 7 } & \multicolumn{2}{|c|}{ After 60 (min) } & \multicolumn{2}{c|}{$\begin{array}{c}\text { After 120 } \\
\text { (min) }\end{array}$} & Total & Ranking \\
\hline CXB-PVP(1:2.5) & 81.88 & 7 & 83.5 & 8 & 15 & 7 \\
\hline CXB-PVP(1:5) & 82.04 & 6 & 93.5 & 5 & 11 & 6 \\
\hline CXB-PVP(1:7.5) & 82.69 & 5 & 94.44 & 4 & 9 & 4 \\
\hline CXB-PVP(1:10) & 90.56 & 3 & 96.93 & 3 & 6 & 3 \\
\hline CXB-Urea(1:2.5) & 60.25 & 12 & 70.40 & 12 & 24 & 12 \\
\hline CXB-Urea(1:5) & 65.02 & 11 & 72.99 & 11 & 22 & 11 \\
\hline CXB-Urea(1:7.5) & 72 & 10 & 79.91 & 10 & 20 & 10 \\
\hline CXB-Urea(1:10) & 73.1 & 9 & 79.96 & 9 & 18 & 9 \\
\hline CXB-HP- $\boldsymbol{\beta}-\mathbf{C D ( 1 : 2 . 5 )}$ & 75.43 & 8 & 85.03 & 7 & 15 & 7 \\
\hline CXB-HP- $\boldsymbol{\beta}$-CD(1:5) & 84.78 & 4 & 89.22 & 6 & 10 & 5 \\
\hline CXB-HP- $\boldsymbol{\beta}-\mathbf{C D ( 1 : 7 . 5 )}$ & 95.22 & 2 & 98.77 & 2 & 4 & 2 \\
\hline CXB-HP- $\boldsymbol{\beta}$-CD(1:10) & 96 & 1 & 99 & 1 & 2 & 1 \\
\hline
\end{tabular}

Table (5): Conclusive rank order for the production yield, drug content, micrometrics properties and in-vitro release of the solid dispersion formulae.

\begin{tabular}{|c|c|c|c|c|c|c|c|c|}
\hline \multirow{2}{*}{$\begin{array}{l}\text { Formula } \\
\text { number }\end{array}$} & \multirow{2}{*}{$\begin{array}{l}(\mathbf{P Y}) \\
\text { RO }\end{array}$} & \multirow{2}{*}{$\begin{array}{l}\text { (DC) } \\
\text { RO }\end{array}$} & \multirow{2}{*}{$\begin{array}{c}(\mathbf{A R}) \\
\mathbf{R O}\end{array}$} & \multirow{2}{*}{$\begin{array}{l}(\mathrm{HR}) \\
\text { RO }\end{array}$} & \multirow{2}{*}{$\begin{array}{l}\text { (CI) } \\
\text { RO }\end{array}$} & \multirow{2}{*}{$\begin{array}{c}\text { (IV release) } \\
\mathrm{RO}\end{array}$} & \multicolumn{2}{|c|}{ Rank Order } \\
\hline & & & & & & & Total & Ranking \\
\hline $\begin{array}{c}\text { CXB- } \\
\text { PVP(1:2.5) }\end{array}$ & 12 & 1 & 11 & 8 & 8 & 7 & 47 & 9 \\
\hline CXB-PVP(1:5) & 11 & 8 & 7 & 3 & 3 & 6 & 38 & 5 \\
\hline $\begin{array}{c}\text { CXB- } \\
\text { PVP(1:7.5) } \\
\end{array}$ & 8 & 5 & 1 & 1 & 1 & 4 & 20 & 2 \\
\hline $\begin{array}{c}\text { CXB- } \\
\text { PVP(1:10) }\end{array}$ & 5 & 2 & 2 & 2 & 2 & 3 & 16 & 1 \\
\hline CXB-U(1:2.5) & 4 & 3 & 8 & 10 & 10 & 12 & 47 & 9 \\
\hline CXB-U(1:5) & 3 & 9 & 9 & 11 & 11 & 11 & 54 & 11 \\
\hline CXB-U(1:7.5) & 1 & 7 & 6 & 7 & 7 & 10 & 38 & 5 \\
\hline CXB-U(1:10) & 2 & 12 & 3 & 6 & 6 & 9 & 38 & 5 \\
\hline $\begin{array}{c}\text { CXB-HP- } \beta \text { - } \\
\text { CD(1:2.5) }\end{array}$ & 10 & 4 & 12 & 12 & 12 & 7 & 57 & 12 \\
\hline $\begin{array}{c}\text { CXB-HP- } \beta \text { - } \\
\text { CD(1:5) }\end{array}$ & 7 & 6 & 10 & 9 & 9 & 5 & 46 & 8 \\
\hline $\begin{array}{c}\text { CXB-HP- } \beta \text { - } \\
\text { CD }(1: 7.5)\end{array}$ & 6 & 11 & 5 & 4 & 4 & 2 & 32 & 3 \\
\hline $\begin{array}{c}\text { CXB-HP- } \beta \text { - } \\
\text { CD(1:10) }\end{array}$ & 9 & 10 & 4 & 5 & 5 & 1 & 34 & 4 \\
\hline
\end{tabular}

PY: Production yield

AR: Angle of repose

DC: Drug content

CI: Compressilbility index

HR: Hausner ratio

RO: Rank order

IV release: In Vitro release 


\section{Kinetic treatment and the kinetic parameters of in-vitro release of Celecoxib and the solid dispersion formulae from Hard gelatin capsule.}

The kinetic treatment of the in-vitro release of Celecoxib is critical and has to be investigated to achieve an optimal system with desired release characteristics. Furthermore, in-vitro release studies are often performed to predict how a delivery system might work in ideal situations, which might give some indication on its in-vivo performance.

Tables (6-8) illustrate the kinetic parameters of the in vitro release of Celecoxib using Hard gelatin capsule. In calculating the kinetic parameters for each order or system, the intercept, the slope, the correlation coefficient, the specific rate constant and the half- life were obtained.

The best kinetic order for the in-vitro release of Celecoxib formulae can be calculated from the highest values of the obtained correlation coefficients, table (9) shows that pure $\mathrm{CXB}$ and all formulae obey the first order kinetics. The highest value of correlation coefficient of Pure CXB was (-0.92748), and for the 12 prepared CXB solid dispersion formulae the best correlation coefficients were: CXB-PVPK30(1:2.5) (-0.97665), CXBPVPK30 (1:5) (-0.99524), CXB-PVPK30 (1:7.5) (-0.98195), CXB-PVPK30 (1:10) (0.97489), CXB-Urea (1:2.5) (-0.98817), CXB-Urea (1:5) (-0.98614), CXB-Urea (1:7.5) (0.98836), CXB-Urea (1:10) (-0.988741), CXB--HP- $\beta$-CD (1:2.5) (-0.98698), CXB--HP- $\beta$ CD (1:5) (-0.97752), CXB--HP- $\beta-C D$ (1:7.5) (-0.97752), CXB-HP- $\beta-C D ~(1: 10)(-0.98324)$, respectively.

Tantishaiyakul et al. (1999) stated that the dissolution rate constants of the first order reaction $\left(\mathrm{min}^{-1}\right)$ of PRXM alone and the solid dispersions were: $0.0025 \mathrm{~min}^{-1}$ for the pure PRXM, $0.0287 \mathrm{~min}^{-1}$ for the drug : PVP K90 in ratio $1: 1,0.0343 \mathrm{~min}^{-1}$ for ratio $1: 2$, $0.0427 \mathrm{~min}^{-1}$ for ratio $1: 3$, and $0.0399 \mathrm{~min}^{-1}$ for ratio $1: 4$.

They stated also that the rate constants in $\min ^{-1}$ for PRXM : PVP K17 were: 0.0305 $\mathrm{min}^{-1}$ for PRXM : PVP K 17 in ratio $1: 1,0.0365 \mathrm{~min}^{-1}$ for ratio $1: 2,0.0545 \mathrm{~min}^{-1}$ for ratio $1: 3$, and $0.1051 \mathrm{~min}^{-1}$ for ratio $1: 4$.

In another research they studied the dissolution rate constants of the pure Nalidixic acid and Nalidixic acid solid dispersions with PVP and $\beta C D$ and they were: $0.00508 \mathrm{~min}^{-1}$ for pure Nalidixic acid, $0.00756 \mathrm{~min}^{-1}$ for drug to PVP in ratio $1: 2.5,0.01990 \mathrm{~min}^{-1}$ for ratio $1: 5,0.0271 \mathrm{mim}^{-1}$ for ratio $1: 7.5,0.02369 \mathrm{~min}^{-1}$ for ratio $1: 10$ and for drug to $\beta C D 0.02077$ for ratio 1:5, $0.04414 \mathrm{~min}^{-1}$ for ratio 1:10. (Mallick et al., 2004)

Shah and co workers (2009) studied the dissolution rates of the solid dispersions of valdecoxib in PEG 4000 and PVP K 30. The correlation coefficients of the valdecoxib solid dispersions were: $0.977 \mathrm{~min}^{-1}$ for valdecoxib: PEG 4000 (1:1), $0.981 \mathrm{~min}^{-1}$ for valdecoxib: PVP K 30 (1:1), and $0.978 \mathrm{~min}^{-1}$ for valdecoxib:PEG 4000:PVP K 30 (1:0.5:0.5).

Punitha et al., (2009) studied the dissolution rates of the solid dispersions of celecoxib in Urea. The correlation coefficients of the celecoxib solid dispersions were: $0.9967 \mathrm{~min}^{-1}$ for CXB-Urea (1:1), $0.99674 \mathrm{~min}^{-1}$ for CXB-Urea (1:3) and $0.9977 \mathrm{~min}^{-1}$ for CXB-Urea (1:5). 
Table (6): Kinetic parameters for the in-vitro release of CXB formulae using hard gelatin capsule according to Zero-order using kinetics

\begin{tabular}{|c|c|c|c|c|c|}
\hline \multirow[b]{2}{*}{$\begin{array}{c}\text { CXB } \\
\text { Formula }\end{array}$} & \multicolumn{5}{|c|}{ Zero-order } \\
\hline & Intercept & Slope & $\begin{array}{c}\text { Correlation } \\
\text { Coefficient } \\
\text { ( r ) }\end{array}$ & $\mathbf{K}$ & $\mathbf{t}^{1 / 2}$ \\
\hline CXB & 41.6765 & 0.18809 & 0.92176 & 0.18809 & 265.83 \\
\hline CXB-PVP(1:2.5) & 56.29611 & 0.249726 & 0.97224 & 0.249726 & 200.22 \\
\hline CXB-PVP(1:5) & 60.64447 & 0.301943 & 0.960269 & 0.301943 & 165.594 \\
\hline CXB-PVP(1:7.5) & 64.80107 & 0.275687 & 0.90662 & 0.275687 & 181.37 \\
\hline CXB-PVP(1:10) & 65.01319 & 0.322127 & 0.912769 & 0.322127 & 155.22 \\
\hline CXB-U(1:2.5) & 41.60276 & 0.246082 & 0.984028 & 0.246082 & 203.18 \\
\hline CXB-U(1:5) & 59.67843 & 0.112189 & 0.984386 & 0.112189 & 445.68 \\
\hline CXB-U(1:7.5) & 59.99894 & 0.171886 & 0.983178 & 0.171886 & 290.89 \\
\hline CXB-U(1:10) & 61.97733 & 0.15725 & 0.974296 & 0.15725 & 317.97 \\
\hline CXB-HP- $\beta$-CD(1:2.5) & 49.24927 & 0.3286 & 0.9564 & 0.3286 & 152.16 \\
\hline CXB-HP- $\beta$-CD(1:5) & 77.81993 & 0.100028 & 0.986055 & 0.100028 & 499.86 \\
\hline CXB-HP- $\beta$-CD(1:7.5) & 87.06391 & 0.107634 & 0.908354 & 0.107634 & 464.54 \\
\hline CXB-HP- $\beta$-CD $(1: 10)$ & 87.80442 & 0.105224 & 0.898192 & 0.105224 & 475.18 \\
\hline
\end{tabular}

Table (7): Kinetic parameters for the in-vitro release of CXB formulae using hard gelatin capsule according to First-order kinetics

\begin{tabular}{|c|c|c|c|c|c|}
\hline \multirow[b]{2}{*}{$\begin{array}{c}\text { CXB } \\
\text { Formula }\end{array}$} & \multicolumn{5}{|c|}{ First-order } \\
\hline & Intercept & Slope & $\begin{array}{c}\text { Correlation } \\
\text { Coefficient } \\
(\mathbf{r})\end{array}$ & $\mathbf{K}$ & $t^{1 / 2}$ \\
\hline CXB & 1.774629 & -0.00181 & -0.92748 & -0.00416 & -166.539 \\
\hline CXB-PVP(1:2.5) & 1.674338 & -0.00406 & -0.97665 & -0.00934 & -74.2061 \\
\hline CXB-PVP(1:5) & 1.67966 & -0.00716 & -0.99524 & -0.0165 & -42.0125 \\
\hline CXB-PVP(1:7.5) & 1.620468 & -0.00717 & -0.98195 & -0.01652 & -41.94 \\
\hline CXB-PVP(1:10) & 1.680707 & -0.01114 & -0.97489 & -0.02566 & -27.0087 \\
\hline CXB-U(1:2.5) & 1.787543 & -0.00254 & -0.98817 & -0.00585 & -118.486 \\
\hline CXB-U(1:5) & 1.611208 & -0.00148 & -0.98614 & -0.0034 & -203.629 \\
\hline CXB-U(1:7.5) & 1.617819 & -0.00261 & -0.98836 & -0.006 & -115.407 \\
\hline CXB-U(1:10) & 1.593069 & -0.00245 & -0.988741 & -0.00563 & -123.004 \\
\hline CXB-HP- $\beta$-CD(1:2.5) & 1.745116 & -0.00485 & -0.98698 & -0.01117 & -62.0397 \\
\hline CXB-HP- $\beta$-CD(1:5) & 1.363526 & -0.00279 & -0.99449 & -0.00642 & -107.974 \\
\hline CXB-HP- $\beta$-CD(1:7.5) & 1.22394 & -0.00879 & -0.97752 & -0.02023 & -34.2477 \\
\hline CXB-HP- $\beta$-CD(1:10) & 1.20852 & -0.00953 & -0.98324 & -0.02195 & -31.566 \\
\hline
\end{tabular}


Table (8): Kinetic parameters for the in-vitro release of CXB formulae using hard gelatin capsule according to Higuchi diffusion model

\begin{tabular}{|c|c|c|c|c|c|}
\hline \multirow{2}{*}{$\begin{array}{c}\text { CXB } \\
\text { Formula }\end{array}$} & \multicolumn{5}{|c|}{ Higuchi diffusion model } \\
\cline { 2 - 6 } & Intercept & Slope & $\begin{array}{c}\text { Correlation } \\
\text { Coefficient } \\
(\mathbf{r})\end{array}$ & K & $\mathbf{t}^{1 / 2}$ \\
\hline CXB & 33.14834 & 2.712758 & 0.925797 & 2.712758 & 339.72 \\
\hline CXB-PVP(1:2.5) & 45.08549 & 3.585336 & 0.972064 & 3.585336 & 194.48 \\
\hline CXB-PVP(1:5) & 46.17776 & 4.467999 & 0.989545 & 4.467999 & 125.23 \\
\hline CXB-PVP(1:7.5) & 50.95418 & 4.172524 & 0.955572 & 4.172524 & 143.596 \\
\hline CXB-PVP(1:10) & 48.70617 & 4.894002 & 0.965723 & 4.894002 & 104.38 \\
\hline CXB-U(1:2.5) & 30.47186 & 3.545247 & 0.987255 & 3.545247 & 198.91 \\
\hline CXB-U(1:5) & 54.67264 & 1.606253 & 0.981484 & 1.606253 & 968.97 \\
\hline CXB-U(1:7.5) & 52.23299 & 2.475032 & 0.985885 & 2.475032 & 408.11 \\
\hline CXB-U(1:10) & 54.775 & 2.278517 & 0.983123 & 2.278517 & 481.54 \\
\hline CXB-HP- $\boldsymbol{\beta}$-CD(1:2.5) & 33.47111 & 4.867452 & 0.98657 & 4.867452 & 105.52 \\
\hline CXB-HP- $\boldsymbol{\beta}$-CD(1:5) & 73.2872 & 1.442278 & 0.99011 & 1.442278 & 1201.83 \\
\hline CXB-HP- $\boldsymbol{\beta}$-CD(1:7.5) & 81.65364 & 1.629644 & 0.957756 & 1.629644 & 941.35 \\
\hline CXB-HP- $\boldsymbol{\beta}$-CD(1:10) & 82.46426 & 1.600601 & 0.951463 & 1.600601 & 975.83 \\
\hline
\end{tabular}

Table (9): The calculated correlation coefficients for the in-vitro release of CXB formulae from hard gelatin capsule employing different kinetic orders or systems

\begin{tabular}{|c|c|c|c|}
\hline \multirow{2}{*}{ CXB Formula } & \multicolumn{3}{|c|}{ Correlation Coefficients (r) } \\
\cline { 2 - 4 } & Zero-order & First-order & $\begin{array}{c}\text { Higuchi's } \\
\text { diffusion model }\end{array}$ \\
\hline CXB & 0.92176 & $\mathbf{- 0 . 9 2 7 4 8}$ & 0.925797 \\
\hline CXB-PVP(1:2.5) & 0.97224 & $\mathbf{- 0 . 9 7 6 6 5}$ & 0.972064 \\
\hline CXB-PVP(1:5) & 0.960269 & $\mathbf{- 0 . 9 9 5 2 4}$ & 0.989545 \\
\hline CXB-PVP(1:7.5) & 0.90662 & $\mathbf{- 0 . 9 8 1 9 5}$ & 0.955572 \\
\hline CXB-PVP(1:10) & 0.912769 & $\mathbf{- 0 . 9 7 4 8 9}$ & 0.965723 \\
\hline CXB-U(1:2.5) & 0.984028 & $\mathbf{- 0 . 9 8 8 1 7}$ & 0.987255 \\
\hline CXB-U(1:5) & 0.984386 & $\mathbf{- 0 . 9 8 6 1 4}$ & 0.981484 \\
\hline CXB-U(1:7.5) & 0.983178 & $\mathbf{- 0 . 9 8 8 3 6}$ & 0.985885 \\
\hline CXB-U(1:10) & 0.974296 & $\mathbf{- 0 . 9 8 8 7 4 1}$ & 0.983123 \\
\hline CXB-HP- $\boldsymbol{\beta}$-CD(1:2.5) & 0.9564 & $\mathbf{- 0 . 9 8 6 9 8}$ & 0.98657 \\
\hline CXB-HP- $\boldsymbol{\beta}$-CD(1:5) & 0.986055 & $\mathbf{- 0 . 9 9 4 4 9}$ & 0.99011 \\
\hline CXB-HP- $\boldsymbol{\beta}$-CD(1:7.5) & 0.908354 & $\mathbf{- 0 . 9 7 7 5 2}$ & 0.957756 \\
\hline CXB-HP- $\boldsymbol{\beta}$-CD(1:10) & 0.898192 & $\mathbf{- 0 . 9 8 3 2 4}$ & 0.951463 \\
\hline
\end{tabular}




\section{CONCLUSION}

This present study showed that when Celecoxib was dispersed in a suitable watersoluble carrier such as HP- $\beta-C D$, PVPK30 and Urea, its dissolution was enhanced compared with pure drug. The water soluble carrier may operate in the microenvironment (diffusion layer) immediately surrounding the drug particles in the early stage of dissolution, since the carrier completely dissolves in short time, enhancing the solubility and dissolution of drug. The study clearly showed that addition of HP- $\beta-C D$ to Celecoxib in ratio 10:1 respectively improved the dissolution rate and this formula ranked first in the in-vitro release rate ranking. Mechanisms involved are solubilization and improved wetting of the drug in the water soluble polymers rich microenvironment formed at the surface of drug crystals after dissolution rate. Finally it could be concluded that solid dispersion of Celecoxib using hydrophilic polymers would improved the aqueous solubility, dissolution rate and thereby enhancing its systemic availability.

\section{REFERENCES}

Ahuja, N., katare, O.P., and Singh B., (2007): Studies on dissolution enhancement and mathematical modeling of drug release of a poorly water-soluble drug using water-soluble carriers. Eur. J. Pharm. Biopharm., 65, 26-38.

Ambike AA, Mahadik KR, and Paradkar A., (2004): Stability study of amorphous valdecoxib. Int J Pharm.282:151-162.

Bley Heike, Bernd Fussnegger, and Roland Bodmeier; (2010): Characterization and stability of solid dispersions based on PEG/polymer blends, International Journal of Pharmaceutics 390 165-173.

British Pharmacopoeia, (2009): The Pharmaceutical Press, London, UK.

Chawlaa, G., Guptaa, P., Thilagavathib, R., and Bansal, A., (2003): Characterization of solid-state forms of Celecoxib, Eur. J.Pharm. Sci. 20(3) 305-317.

Chowdary, K. and Srinivas, S., (2006): Influence of Hydrophilic Polymers on Celecoxib Complexation with Hydroxypropyl $\quad \beta$-Cyclodextrin. AAPS Pharm.Sci.Tech.; 7(3): Article 79, 184-189.

Dahiya Sunita, (2010): Studies on formulation development of a poorly water-soluble drug through solid dispersion technique, Thai J. Pharm. Sci. 34 -77-87.

Dixit, R. and Nagarsenker, M., (2007): In vitro and in vivo advantage of celecoxib surface solid dispersion and dosage form development, Ind. J. Pharm. Sci.; 69:370-7.

Ford, J., Stewart, A. and Dubo, J., (1986): The properties of solid dispersions of indomethacin or phenylbutazone in polyethyleneglycol , Int. J.Pharm., 28,(1),1122.

Higuchi, T., (1963): Mechanism of sustained action medication, theoretical analysis of rate of release of solid drugs dispersed in solid matrices, J. Pharma. Sci., 52, 11451149.

Joe J. H., Won M. L., Young-Joon P., Kwan H. J., Dong H. O., Youn G. S., Jong S. W., Chul So. Y., and Han-Gon C., (2010): Effect of the solid-dispersion method on the solubility and crystalline property of Tacrolimus, International Journal of Pharmaceutics 395 - 161-166. 
Maestre, I., Beà, I., Ivanov, P., and Jaime, C., (2007): Structural Dynamics of Some Large-Ring Cyclodextrins. A Molecular Dynamics Study: An Analysis of Force Field Performance, Theor. Chem. Acc., 117 (13) 85-97.

Muralidhar, S., Devala, G., Rao, Syed Azhar Nizami, Karunakara Reddy.T., and Ravindra, S., Reddy, (2010): Enhancement of dissolution rate and antiinflammatory potential of celecoxib using solid dispersion Technique, Journal of Advanced Pharmaceutical Research., 1, 74-81.

Mallick, S., Ashok, S., and Kanshik, P., (2004): Dissolution Behaviour Of Nalidixic Acid Solid Dispersions Using Water Soluble Dispersion Carriers, Pharmceutica-Drug Research, Vol 61, No.1, PP 21-30.

Paradkar A, Ambike AA, Jadhav BK, and Mahadik KR., (2004): Characterization of curcumin-PVP solid dispersion obtained by spray drying. Int J Pharm.;271:281286.

Patel T.B., Patel, L.D., Makwana, S.H., and Patel, T.R., (2010a): Formulation And Characterization Solid Dispersions Containing Glibenclamide, Int J Pharmacy and Pharm Sci, 2, (3), 138-141.

Patel R.C., Keraliya, R.A., Patel, M.M., and Patel, N.M, (2010b): Formulation of furosemide solid dispersion with micro crystalline cellulose for achieve rapid dissolution, J. Adv. Pharm. Tech. Res., 1, (2).

Patlolla, R., Chougule, M., Patel, A., Jackson, T. and Singh, M., (2010): Formulation, characterization and pulmonary deposition of nebulized Celecoxib encapsulated nanostructured lipid carriers, Journal of Controlled Release,144( 2) 233-2411.

Pouton, C.W., (2006): Formulation of poorly water-soluble drugs for oral administration: physicochemical and physiological issues and the lipid formulation classification system. Eur. J. Pharm. Sci., 29, 278-287.

Punitha, S., Karthikeyan, D., Devi, P., and Vedha Hari, B., N., (2009): Enhancement of Solubility and Dissolution of Celecoxib by Solid Dispersion Technique, Journal of Pharmaceutical Science and Technology Vol. 1 (2), 63-68.

Punitha S., Vedha Hari, B., N., and Karthikeyan D., (2010): Enhancement of Celecoxib solubility by solid dispersion using mannitol, International Journal of Pharmacy and Pharmaceutical Sciences, Vol 2, Issue 4, (2010).

Samy, A., M., Marzouk, M., A., Ammar, A., A., and Ahmed, M., K., (2010): Enhancement of the dissolution profile of allopurinol by a solid dispersion technique, Drug Discoveries \& Therapeutics., 4(2):77-84.

Seedher, N., and Bhatia, S., Solubility Enhancement of Cox-2 Inhibitors Using Various Solvent Systems. AAPS PharmSciTech.; 4(3): article 33 (2003).

Sekiguchi, K., and Obi, N., (1961): Studies on Absorption of Eutectic Mixture. I. A comparison of the behaviour of eutectic mixture of sulfathiazole and that of ordinary sulfathiazole in man, Chem. Pharm. Bull., 9: 866-872.

Sekiguchi, K. and Obi, N., (1964): Studies on Absorption of Eutectic Mixture. Ii. Absorption of Fused Conglomerates of Chloramphenicol and Urea in Rabbits.Chem. Pharm. Bull (Tokyo) 12, 134-144. 
Shah, J., Vasanti, S., Anroop, B., and Vyas, A.V., (2009): Enhancement of dissolution rate of valdecoxib by solid dispersions technique with PVP K 30 \& PEG 4000: preparation and in vitro evaluation, J Incl Phenom Macrocycl Chem., 63:69-75.

Shakeel, F., Baboota, S., Ahuja, A., Ali, J., and Shafiq, Sh., (2008): Skin permeation mechanism and bioavailability enhancement of celecoxib from transdermally applied nanoemulsion,J.Nanobiotech. 6, 1477-3155.

Shavi, G., Kumar, A., and Usha, Y., (2010): Enhanced dissolution and bioavailability of gliclazide using solid dispersion techniques, Int. J. Drug Deliv., 2, 49-57.

Simonelli, A., P., Mehta, S., C., and Higuchi, W., I., (1976): Dissolution rates of high energy sulfathiazole-povidone coprecipitate II: characterization of form of drug controlling its dissolution rates via solubility studies. J. Pharm. Sci. 65, 355-361.

Tantishaiyakul, V., Kaewnopparat, N., and Ingkatawornwong, S., (1999): Properties of solid dispersions of piroxicam in polyvinylpyrrolidone, Int. J. of Pharm., 181 143-151.

Tran, T., T., Phuong H., L., Tran, Han-Gon C., Hyo-Kyung, H., and Beom-Jin L., (2010): The roles of acidifiers in solid dispersions and physical mixtures, International Journal of Pharmaceutics 384, 60-66.

United States Pharmacopoeia, (2007): USP 30/NF 25, the USP Convention, Rockville, pp 2960.

Venkatesh, G., S., Averineni, R., K., Yogendra, N., U., Karthik, A., Om prakash R., Kishore G., Sureshwar P., and Nayababhirama U., (2010): Enhanced dissolution and bioavailability of gliclazide using solid dispersion techniques, International Journal of Drug Delivery 2, 49-57.

Tiwari Vijay, Dhana jay kinikar, Krishna Pillai, and P., D., Gokulan, (2010): Preparation and Evaluation of Fast Dissolving Tablets of Celecoxib, Journal of Current Pharmaceutical Research 04, 4-10.

Wagner, S., G., (1975): Fundamentals of Clinical Pharmacokinetics (1st Ed.), Drug Intelligence Publications Inc., Hamilton, Illinois, 71.

Yang, M., Wang, P., Huang, C., Y., Ku, M., S., Liu, and H., Gogos, C., (2010): Solid dispersion of acetaminophen and poly(ethylene oxide) prepared by hot-melt mixing, International Journal of Pharmaceutics 395 - 53-61. 
المشتقات الصلبة لعقار السيلكوكسيب و المحضرة بطريقة تبخير المذيب

ياسمين إسماعيل مرتجى' ، شديد جاد شديد'، ممدوح مصطفي غرابَ، أحمد محمود ساميّ

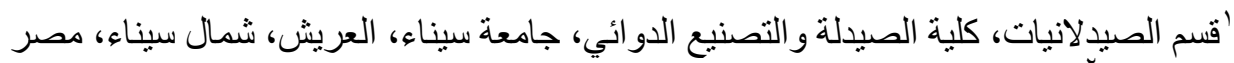

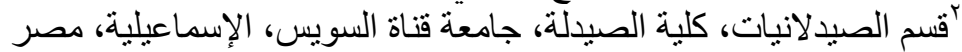

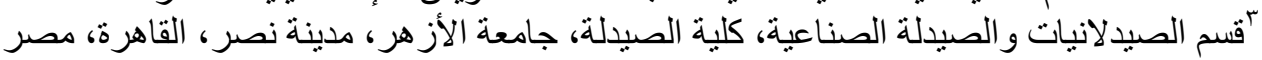

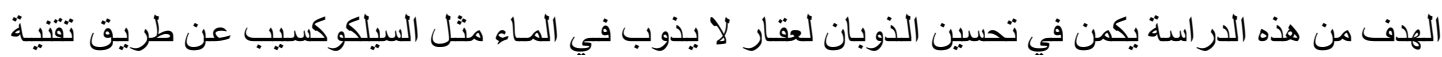

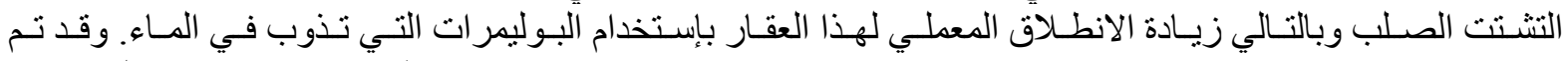

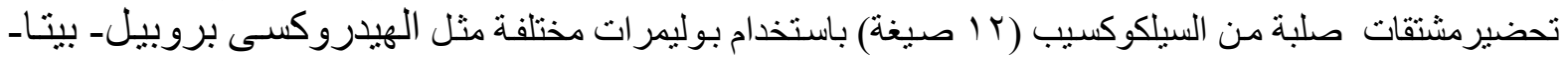

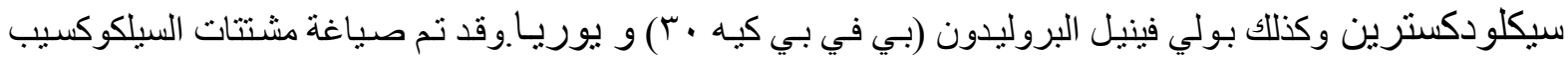

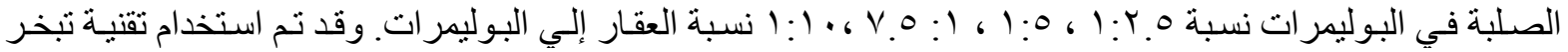

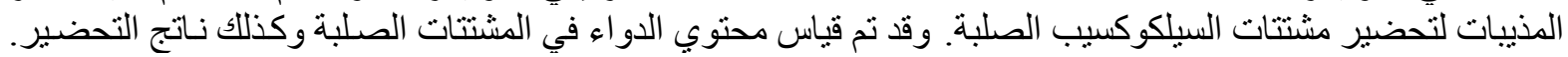

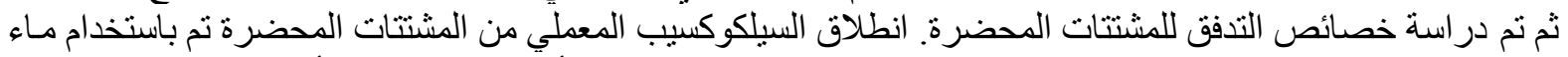

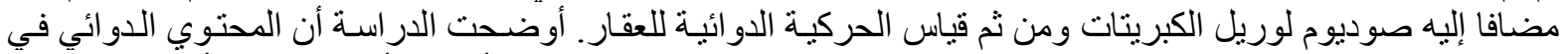

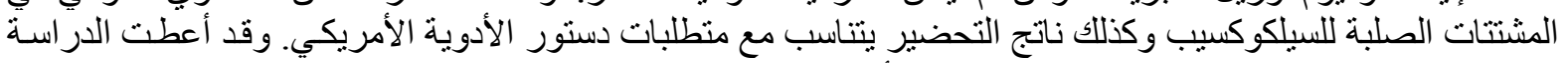

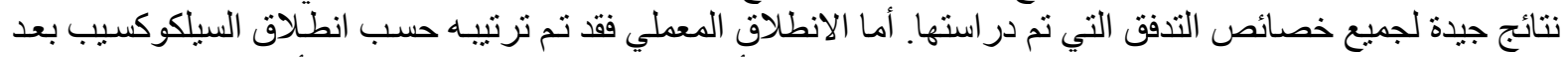

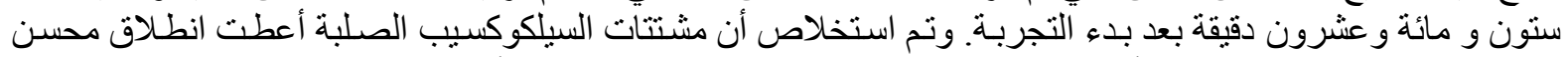

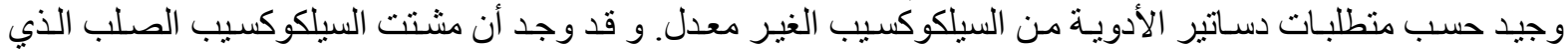

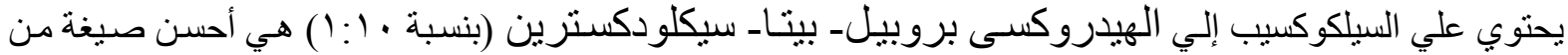

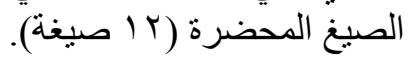

